\title{
BMJ Open Development and application of a chronic kidney disease-specific health literacy, knowledge and disease awareness assessment tool for patients with chronic kidney disease in Taiwan
}

\author{
Chung-Jen Wei, ${ }^{1}$ Chung-Liang Shih, ${ }^{2}$ Yu-Juei Hsu, ${ }^{3}$ Yin-Cheng Chen, ${ }^{4}$ \\ Jue-Zong Yeh, ${ }^{5}$ Jia-Hui Shih, ${ }^{6}$ Chiung-Hsuan Chiu (D) ${ }^{6}$
}

To cite: Wei C-J, Shih C-L, Hsu Y-J, et al. Development and application of a chronic kidney disease-specific health literacy, knowledge and disease awareness assessment tool for patients with chronic kidney disease in Taiwan. BMJ Open 2021;11:e052597. doi:10.1136/ bmjopen-2021-052597

- Prepublication history and additional supplemental material for this paper are available online. To view these files, please visit the journal online (http://dx.doi.org/10.1136/ bmjopen-2021-052597).

Received 25 April 2021 Accepted 24 September 2021

Check for updates

(C) Author(s) (or their employer(s)) 2021. Re-use permitted under CC BY-NC. No commercial re-use. See rights and permissions. Published by BMJ.

For numbered affiliations see end of article.

Correspondence to Dr Chiung-Hsuan Chiu; meg_chiu@tmu.edu.tw

\section{ABSTRACT}

Objectives This study aims to develop an assessment tool for health literacy and knowledge specific to chronic kidney disease (CKD) for use in examining the associations between health literacy, disease-specific knowledge and disease awareness among patients with CKD in Taiwan.

Design An assessment tool in Mandarin and Taiwanese was developed based on patient input, panel discussions with experts and a literature review, and checked for validity and reliability in a pilot test. Formal data were collected through population-based sampling with a set quota according to region and hospital accreditation level. Cross-sectional data were collected to confirm the reliability and validity of the assessment tool. Levels of health literacy, disease knowledge, and disease awareness were then reported and analysed.

Setting Sample hospitals included 10 medical centres, 18 regional hospitals and 15 local hospitals in Taiwan. Researchers were granted Internal Review Board approval and obtained agreement to collect data in all study settings.

Participants Patients at least 20 years old who had been diagnosed with CKD of any stage were eligible to participate. The formal assessment collected 1155 valid questionnaires, yielding an $87.3 \%$ response rate. The mean age of participants was 67.48 years $(S D=12.87$, range 22-98), while 484 (41.95\%) were female and 78\% were aware they had CKD.

Results The self-devised instrument proved to have excellent reliability and validity. Use of the instrument in the main study showed that CKD-specific health literacy was significantly associated with age $(\beta=-0.33$, $p<0.00$ ), educational attainment and disease awareness $(\beta=0.13, p<0.00)$. CKD-specific knowledge was also significantly associated with age $(\beta=-0.18, p<0.00)$, educational attainment and disease awareness $(\beta=0.19$, $\mathrm{p}<0.00$ ).

Conclusions This CKD-specific health literacy and knowledge assessment tool developed for Mandarin and Taiwanese-speaking patients is reliable and well validated. Patients with CKD who are aware of and understand their disease performed better in the assessment.

\section{STRENGTHS AND LIMITATIONS OF THIS STUDY}

$\Rightarrow$ To our knowledge, there are few disease-specific health literacy instruments with which to compare our assessment.

$\Rightarrow$ This nationwide study only provides an initial understanding of health literacy, disease knowledge and disease awareness among patients with chronic kidney disease (CKD).

$\Rightarrow$ The results only apply to Taiwanese patients with CKD, with limited generalisability to global populations.

\section{BACKGROUND}

Chronic kidney disease (CKD), often called a 'silent epidemic' for its difficulty to detect, is regarded as one of the most significant chronic diseases in the world. This quiet killer is especially prevalent in Taiwan, which in 2018 reported the highest incidence of treated end-stage renal disease (ESRD) in the world at 523 people per million compared with 395 per million in the USA, according to an annual report by the US Renal Data System (USRDS). ${ }^{1}$ Not only did Taiwan record the world's highest rate, but it is also climbing, growing $6.1 \%$ between 2003 and $2016 .^{2}$ In 2017, NT $\$ 503.63$ billion (US $\$ 1=\mathrm{NT} \$ 27.93$ ) was spent on acute and chronic kidney diseases, accounting for the largest portion of the country's National Health Insurance expenditures. Approximately NT $\$ 433$ billion was spent on dialysis alone, ${ }^{3}$ not to mention the costs associated with lost productivity.

Slowing the progression of CKD relies on patients taking responsibility for their own care, including following nephrologists' instructions on diet, fluid intake and exercise. ${ }^{45}$ Success therefore hinges on key factors such as health literacy, adherence behaviour 
and disease awareness, as well as a commitment to accommodating CKD. ${ }^{46}$ Among these factors, disease awareness is especially crucial, as it helps patients understand risk and accept their disease, and ensures they are willing to learn from and cooperate with health providers. Good disease awareness enhances health literacy, thereby helping patients better manage their condition. ${ }^{57}$

Disease awareness is defined as understanding individual risk, disease status and disease history, as well as fully committing to managing a disease ${ }^{8-10}$ Patients with chronic diseases are expected to take an active role in managing their illness and understanding risk to slow its progression. Patients must also learn disease-specific information to best make their own judgements on questions of care. However, CKD awareness among patients is low according to previous studies and our own clinical observations. ${ }^{10}$ In Taiwan, the national prevalence of CKD as of 2006 was $11.93 \%$, but only $3.54 \%$ of the participants in one study were aware of their condition. ${ }^{11}$

Once disease awareness is improved, health literacy may follow. As defined by the American Medical Association, health literacy is 'a constellation skill, including the ability to perform basic reading and numerical tasks required to function in the healthcare environment. ${ }^{12}$ According to Nutbeam, health literacy encompasses three domains: basic/functional literacy, communicative/interactive literacy and critical literacy, including cognitive and social skills that incorporate the abilities required to read, comprehend and analyse information. ${ }^{13}$ As health literacy significantly affects healthy lifestyle choices and adherence, ${ }^{14}$ enhancing patients' health literacy could lead to better physician-patient communication and more effective utilisation of medical resources, ultimately improving patients' self-management behaviour and health outcomes. ${ }^{15-18}$

There are already some commonly used tools to measure health literacy, such as the Test of Functional Health Literacy in Adults, ${ }^{19}$ Newest Vital Sign,${ }^{20}$ the European Health Literacy Survey ${ }^{21}$ and the Health Literacy Questionnaire. ${ }^{22}$ A systematic review of studies measuring CKD literacy revealed that most researchers used the Rapid Estimate of Adult Literacy in Medicine, the Short Test of Functional Health Literacy or the Brief Health Literacy Screen. ${ }^{23}$ As for health knowledge, some assessment tools have been designed specifically for patients with CKD, including the Perceived Kidney Knowledge Survey and objective knowledge tool, and the Kidney Disease Knowledge Survey (KiKS) developed by Wright et $a .^{24}$ Believing that disease-related knowledge should include perceived knowledge (what patients actually know) in addition to objective knowledge (what patients expect to know), Wright et aldeveloped KiKS based on the Kidney Disease Outcomes Quality Initiative Guidelines. ${ }^{25}$ Two other researchers, Devraj and Wallace, developed a Chronic Kidney Disease Self-Management Knowledge Tool to measure how well patients understand kidney disease and self-management behaviour. ${ }^{26}$ However, few instruments have been designed to measure CKD-specific health literacy, with most health professionals instead using general literacy instruments. ${ }^{23} 27$ In addition to CKD-specific health education, health literacy is also crucial to ensure that patients with CKD understand their illness and can make decisions based on this knowledge.

To better understand and identify health literacy among patients with CKD, we have developed a tool to assess CKD-specific health literacy for Mandarin and Taiwanese speakers. Data collected using the assessment tool were then used to examine associations between health literacy, disease-specific knowledge and disease awareness among patients with CKD in Taiwan, suggesting a need for earlier intervention to improve health literacy and thereby delay progression into ESRD.

\section{METHODS}

\section{Study design}

First, an assessment tool for measuring CKD-specific health literacy was developed for Mandarin and Taiwanese speakers based on patient input, panel discussions and a literature review, ${ }^{24} 28-30$ and checked for validity and reliability in a pilot test. Formal data using the tool were collected through population-based sampling with a set quota according to region and hospital accreditation level. Cross-sectional data were collected to confirm the reliability and validity of the assessment tool. Levels of health literacy, disease knowledge, and disease awareness were then assessed and analysed.

\section{Study population and sample}

This study used Taiwan's National Health Insurance database (2010-2014) to estimate the number of patients with CKD in Taiwan. After determining there were about 870000 people 20 years or older with CKD over the 4-year period, the 'International Classification of Disease 9th revision (ICD-9) code' as defined by the USRDS and Taiwan's National Health Insurance Administration was used to determine inclusion criteria. ${ }^{31}{ }^{32}$ The sample size was based on the equation $n=\frac{\frac{z^{2} \cdot p(1-p)}{z^{2}}}{1+\left(\frac{z^{2} \cdot p(1-p)}{z^{2} N}\right)}$ and maintained a $95 \%$ level of confidence with a margin of error of $\pm 3 \%$. The process suggested a sample size of 1067 to represent the total population of patients with CKD in Taiwan ( $\mathrm{N}=$ population size; $\mathrm{e}=$ margin of error; $\mathrm{p}=\mathrm{de}-$ sired vol/population; $\mathrm{z}=\mathrm{Z}$ score).$^{33}$

The 1067 suggested samples were weighted proportionally by hospital accreditation level (medical centre, regional hospital and district hospital) and hospital region (northern, central, southern, eastern and outlying island). After confirming the distribution of the total population, data were collected in 43 sample hospitals, including 10 medical centres, 18 regional hospitals and 15 local hospitals in Taiwan. Researchers were granted Internal Review Board approval and obtained agreement to collect data in all study settings. Data were collected in face-to-face interviews from March to November 2017. Interviewers 
were trained before the study began. For inclusion in the study, participants had to be at least 20 years old and have been diagnosed with CKD of any stage. Patients who had received dialysis treatment, were pregnant or were unable to respond to questionnaires were excluded. This study did not exclude patients with comorbidities such as high blood pressure, diabetes or high hyperlipidaemia, with details included in the demographics section. Patients on dialysis were excluded because the guidelines and intensity of dialysis care differ greatly from CKD care. ${ }^{34}$ This study instead focuses on patients with CKD whose disease progress could be slowed by better health literacy and disease management.

Nephrologists agreed to refer patients with CKD who met the inclusion criteria to researchers immediately following a doctor visit. Once eligible candidates agreed to participate, they were referred to a researcher who was waiting outside the nephrology clinic. Interviewers first explained the purpose of the study, then invited eligible subjects to participate. After disclosing it would take about 20-25 min to complete the survey, the interviewers obtained oral and written consent, leaving eligible participants free to choose whether to participate.

\section{Instrument development and validation}

Instrument development

An instrument in Mandarin and Taiwanese to assess CKD-specific health literacy and knowledge was developed based on a literature review, four focus groups with patients and panel discussions with physicians. The literature review confirmed the current definition and tools to measure CKD-specific health literacy and knowledge. Meanwhile, the focus groups served to assess concerns and habits of patients with CKD, while panel discussions with experts assessed the difficulties faced by physicians treating CKD.

For the focus groups, a total of 16 patients with CKD (9 men and 7 women) were referred by nephrologists to share their cognitive experiences of the disease, adherence behaviour, and how they select and respond to health-related information. Only patients in the early stages of CKD who regularly visit nephrologists were included. Age, gender and success with disease management were also taken into consideration to ensure group heterogeneity. Four focus groups were held in hospitals located in northern, central, southern and eastern Taiwan in order to mitigate possible effects of geographical variance on the results. Participants were informed and gave consent to participate prior to the start of the focus groups. All interviews were conducted in spare hospital rooms and each took $90-120 \mathrm{~min}$ to complete. Interview guidelines are included in online supplemental appendix 1. All focus groups were audio recorded and transcribed verbatim, then coded by two authors. The codes were then checked and retained when inter-rater reliability exceeded 0.8. Data saturation was confirmed when no new themes emerged in the third and fourth focus groups. Qualitative results of the focus groups revealed three findings: participants who denied their illness were reluctant to follow doctors' orders; participants understood the importance of maintaining a healthy diet, but only a few followed recommendations; and patients were most likely to maintain a healthy lifestyle with sufficient social support.

Confirmed by expert panels and a literature review, researchers concluded that the most important determinants to successful CKD management are disease awareness, health literacy and knowledge, and demography. These key factors then guided the development of a CKDspecific health literacy questionnaire.

Basic/functional literacy refers to basic literacy and cognitive abilities, such as the reading and writing skills needed to function effectively in daily life. Communicative/interactive literacy refers to more advanced cognitive skills, such as the ability 'to extract information and derive meaning from different forms of communication, and to apply new information to changing circumstances'. ${ }^{12}$ Advanced/critical literacy refers to the ability to "critically analyse information, and to use this information to exert greater control over life events and situations'. ${ }^{13}$

The 'disease awareness' category of questions (three items) in the questionnaire was designed to measure whether patients know they have an illness and if they have changed their daily behaviour to manage it. Questions were as follows: 'Do you have CKD or a related disease?' (Yes/No), 'Does this illness impact your lifestyle?' (Yes/ No), and 'Have you changed your lifestyle to manage this illness?' (Yes/No).

The 'CKD-specific health literacy' category consisted of questions intended to measure functional (four items), communicative (eight items) and critical (five items) health literacy, defined respectively as the ability to understand an illness, communicate effectively and make judgements based on facts. ${ }^{13}$ The 12 items were presented as a multiple-choice cloze test, with one point awarded for each correct response. The questions were written based on reading materials from the US National Kidney Disease Education Program and the Health Promotion Administration (HPA) of Taiwan's Ministry of Health and Welfare. ${ }^{35} 36$

'Disease-specific knowledge' questions tested participants on basic kidney functionality (four items), kidney disease prevention (three items), healthy lifestyle habits (five items), diet (four items) and medication (two items) based on reading materials prepared for KiKS and by the HPA. ${ }^{25} 36$ The 21 items were presented as true-or-false questions, with a 'do not know' option. One point was given for each correct answer.

Demographic data included gender, age, educational attainment, area of residence, socioeconomic status, disease history, CKD stage and accreditation level of hospitals visited.

\section{Validation}

Face validity was checked by a three-round Delphi method. Sixteen experts-four nephrologists (MD/ 
$\mathrm{PhD}$ ), two pharmacists, two dietitians, three nurses/ health educators and five professors with PhDs-were invited to score items, revise wordings and allocate items to the appropriate dimensions. Scores ranged from 1 to 3 , with 1 meaning remove the item, 2 recommending revision and 3 meaning keep the item without revision. Items that averaged a score of 2 or higher were kept.

\section{Pilot test}

For the pilot test, 50 eligible participants were selected from a medical centre, regional hospital and district hospital in the Taipei area. The majority were men $(\mathrm{n}=34,68 \%)$ and average age was 67.84 years $(\mathrm{SD}=13.90$, range $=37-93$ ). Kuder-Richardson Formula 20 (KR-20) results for health literacy and disease-specific knowledge were 0.78 and 0.76 , respectively, ${ }^{37}$ indicating good reliability. Data collected in the pilot test were not included in the main study.

\section{Statistical analysis}

Construct validity of CKD-specific health literacy and knowledge was checked through confirmatory factor analysis. Descriptive statistics were reported for demographic variables, disease awareness, CKD-specific health literacy and disease-specific knowledge. A t-test/ One-way analysis of variance (ANOVA) was used to report bivariate association of the study variables. After ensuring that the study variables were normally distributed, the relationship between literacy, disease knowledge and disease awareness by healthcare facility accreditation was determined through multiple regression. Data were analysed using the IBM SPSS V.22.0 and LISREL V.9.3.
Patient and public involvement

Patients and the public were not involved in this study.

\section{RESULTS}

\section{Construct validity and reliability}

To confirm construct validity, the factorial structure of the items was tested by confirmatory factor analysis. Based on the model fit index, two items relating to CKD-specific knowledge were deleted to ensure best fit (table 1), leaving 17 items to measure health literacy and 16 items to measure CKD-specific knowledge. Confirmatory factor analysis coefficients are shown in figures 1 and 2. The KR-20 reliability of health literacy and CKD-specific knowledge were 0.68 and 0.81 , respectively.

\section{Descriptive statistics}

A total of 1155 questionnaires were collected from 1323 eligible candidates, yielding an $87.3 \%$ response rate and surpassing the original goal of collecting 1067 valid questionnaires with a response rate of $85 \%$. The mean age of participants was 67.48 years $(\mathrm{SD}=12.87$, range $22-98)$ and the mean time since diagnosis with CKD was 5.33 years $(\mathrm{SD}=6.38$, range $0-60)$. Slightly more than half of the participants $(58.1 \%)$ were men, and $57.2 \%$ had attained at least high school education. By disease level, $5.5 \%$ were in stage $1,13.0 \%$ were in stage $2,16.7 \%$ were in stage $3 \mathrm{~A}, 26.1 \%$ were in stage $3 \mathrm{~B}, 20.2 \%$ were in stage 4 and $18.4 \%$ were in stage 5 . Regarding comorbidities, $70.6 \%$ reported also having hypertension, while $49.6 \%$ reported having diabetes. Although $75.9 \%$ of the participants had been educated by medical staff, $22.0 \%$ reported a lack of disease awareness. All missing data were identified and corrected during interviews.

Table 1 Confirmatory factor analysis-model fitting index

\begin{tabular}{|c|c|c|c|}
\hline & CKD-specific health literacy & Disease-specific knowledge & Fitting index \\
\hline \multicolumn{4}{|c|}{ Overall model fit } \\
\hline $\mathrm{X}^{2}$ & 495.04 & 435.48 & Smaller is better \\
\hline \multicolumn{4}{|l|}{ Absolute fit } \\
\hline GFI & 0.95 & 0.95 & $>0.9$ \\
\hline \multicolumn{4}{|c|}{ Comparative fit } \\
\hline NNFI & 0.84 & 0.95 & $>0.9$ \\
\hline CFI & 0.86 & 0.96 & $>0.9$ \\
\hline ECVI & 0.49 & 0.45 & Smaller is better \\
\hline \multicolumn{4}{|c|}{$\begin{array}{l}\mathrm{X}^{2} \text {, Chi-square; AGFI, Adjusted Goodness of Fit Index; CFI, Comparative Fit Index; CKD, chronic kidney disease; ECVI, Expected cross- } \\
\text { validation Index; GFI, Goodness of Fit Index; NNFI, Non-Normed Fit Index; PGFI, Parsimonious Goodness Fit Index; PNFI, Parsimonious } \\
\text { Normed Fit Index; RMSEA, Root Mean Square Error of Approximation. }\end{array}$} \\
\hline
\end{tabular}




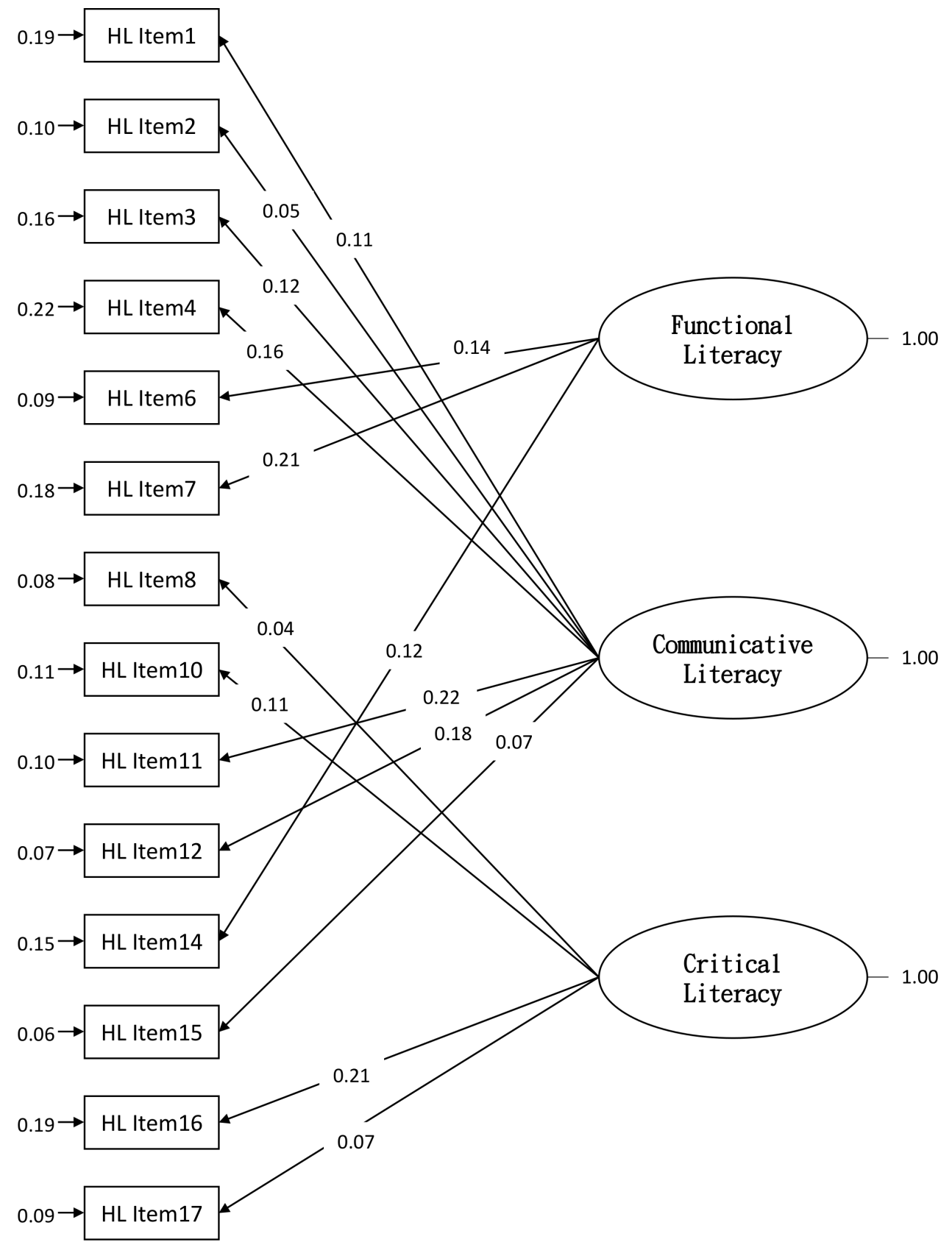

Figure 1 Confirmatory factor analysis of the three dimensions of chronic kidney disease-specific health literacy (HL).

Mean scores were $4.06(\mathrm{SD}=1.19$, range $0-5)$ for functional literacy, $4.12(\mathrm{SD}=2.01$, range $0-7)$ for communicative literacy, $2.57(\mathrm{SD}=1.75$, range $0-5)$ for critical literacy and 8.75 ( $\mathrm{SD}=5.70$, range $0-17$ ) for total health literacy. Mean scores for CKD-specific knowledge were 2.30 ( $\mathrm{SD}=0.97$, range $0-3)$ for basic knowledge, 2.35 ( $\mathrm{SD}=0.93$, range $0-3)$ for prevention, $3.22(\mathrm{SD}=0.97$, range $0-4)$ for lifestyle, $2.50(\mathrm{SD}=1.17$, range $0-4)$ for dietary intake, 1.30 $(\mathrm{SD}=0.67$, range $0-2)$ for medication and $11.67(\mathrm{SD}=3.44$, range $0-16$ ) for overall CKD knowledge.

\section{Bivariate analysis}

Male participants recorded significantly higher rates of communicative health literacy, critical health literacy and basic kidney knowledge than women (table 2).
Participants who were younger, had higher educational attainment or previous health education, and were aware of having CKD recorded better CKD-specific health literacy and knowledge.

There was no significant correlation between CKD awareness and gender or age, but CKD stage and previous health education had a significant effect. Disease awareness was relatively split among those in stages 1 and 2, with 36 of the participants in stage 1 saying they were aware of their disease and 28 saying they were not, while 88 in stage 2 said they were aware and 60 said they were not. Participants in pre-ESRD stages were slightly more aware of their disease, but the greatest jump occurred at 


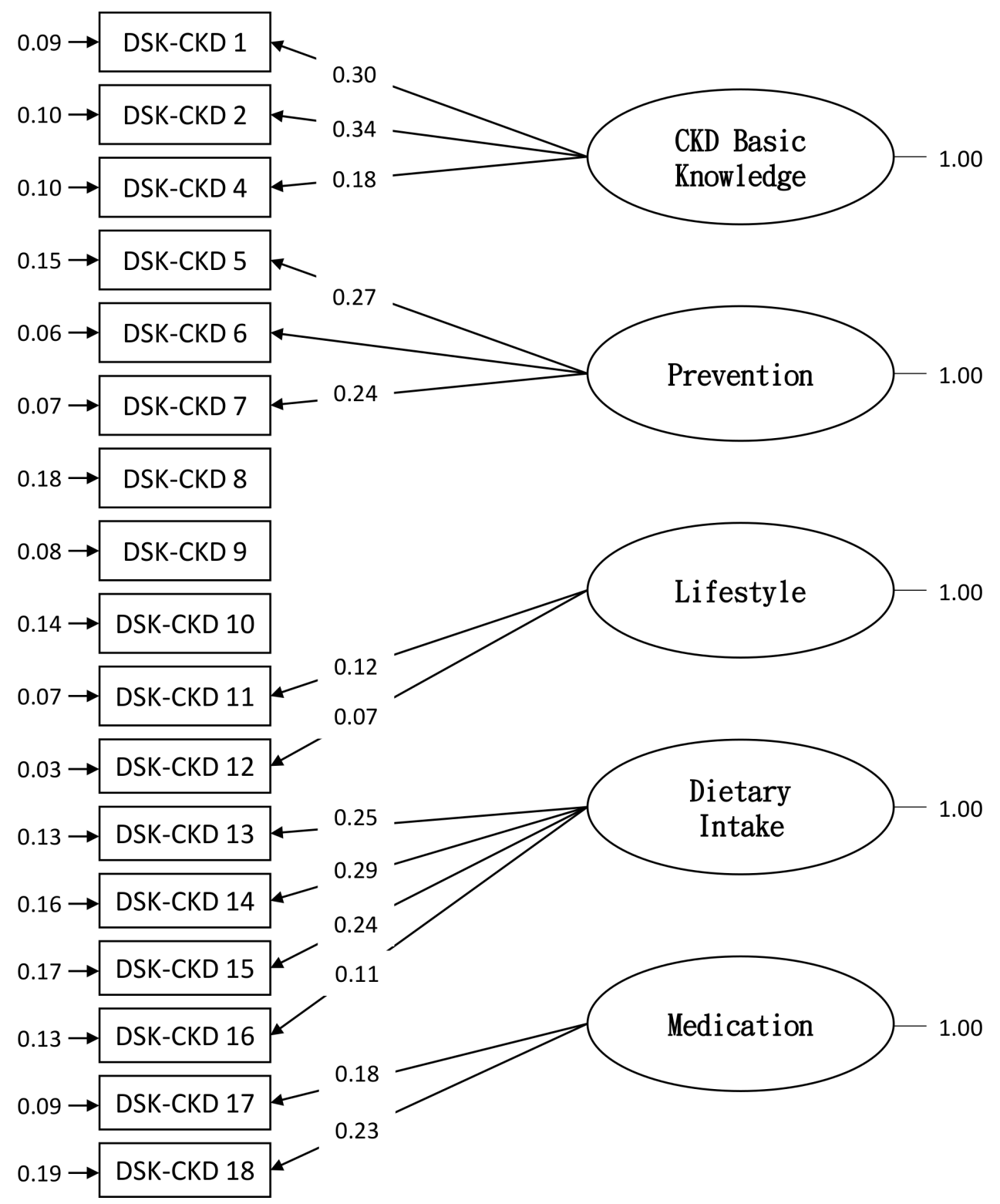

Figure 2 Confirmatory factor analysis of the five dimensions of disease-specific knowledge of chronic kidney disease (DSKCKD).

stage 5, with 184 reporting awareness to only 29 who said they were unaware of their condition.

\section{Regression analysis}

Linear regression was employed to explore the relationships between demographic variables, CKD awareness, and CKD-specific health literacy and knowledge (table 3). The results show that CKD-specific health literacy was significantly associated with age $(\beta=-0.33, p<0.00)$, educational attainment and disease awareness $(\beta=0.13, p<0.00)$. It was also linked to disease stage, as participants in stage 5 presented significantly worse health literacy than participants in stage 1. CKD-specific knowledge was also significantly associated with age $(\beta=-0.18, p<0.00)$, educational attainment and disease awareness $(\beta=0.19, \mathrm{p}<0.00)$, although there was no significant correlation between CKD stage and disease-specific knowledge.

\section{DISCUSSION}

\section{Instrument and major findings}

This CKD-specific health literacy and knowledge assessment tool in Mandarin and Taiwanese developed to enable better management of CKD by measuring basic/ functional, communicative, and critical literacy and knowledge proved to have very good reliability and validity. We therefore recommend its use in assessing the overall health literacy and knowledge of patients with CKD to identify deficiencies and better target educational efforts. $^{38}$

Although health literacy has been criticised for its poor definition and tenuous connection to health promotion, ${ }^{39}$ many studies have managed to redefine its frameworks and enhance its feasibility, enabling its use as a tool in bridging the gap between patients and healthcare 


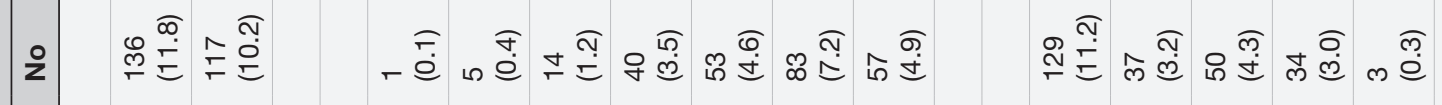

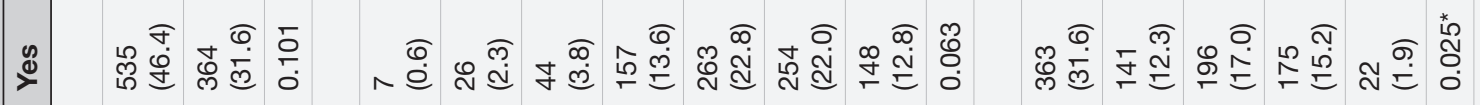

\&

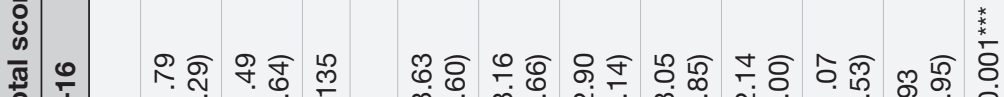

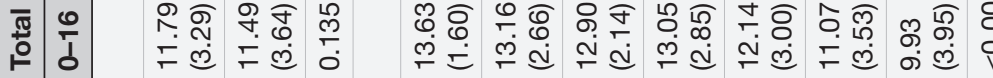

œ

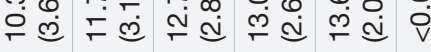

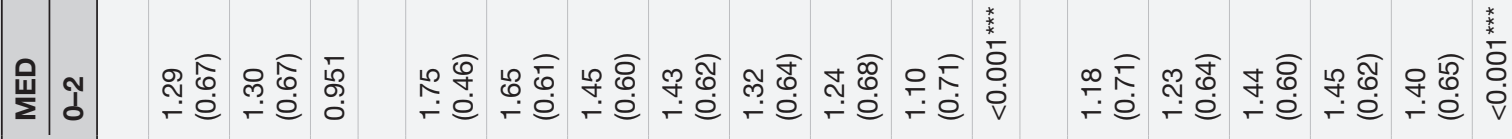

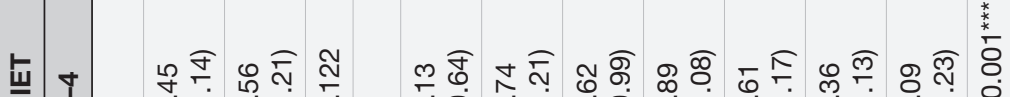

Nָi

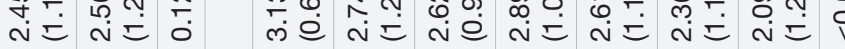

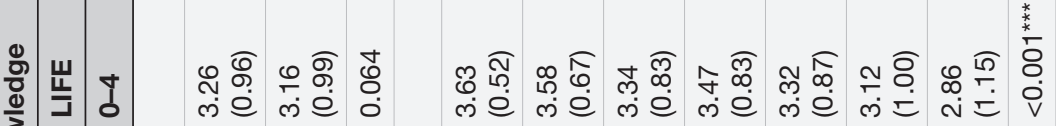

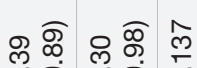

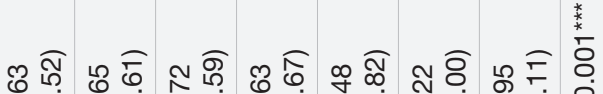

웡

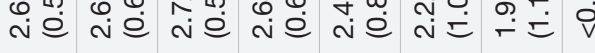

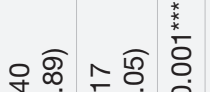

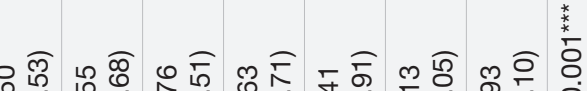

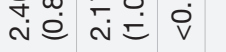

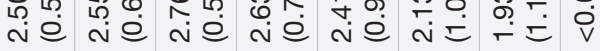

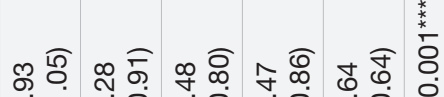

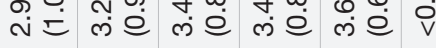
Nं

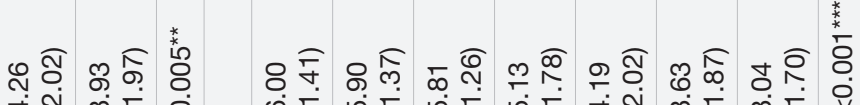
Ұำ

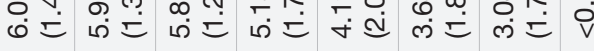

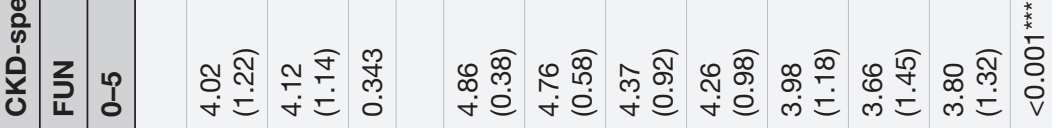

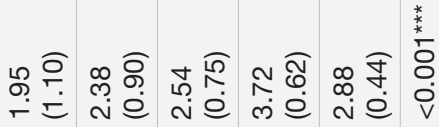
ம் 
ப்t

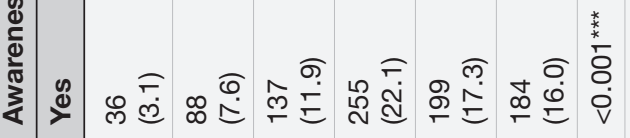

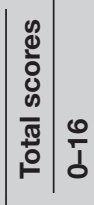

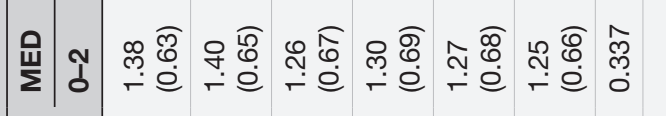

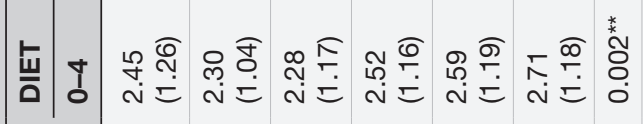

离

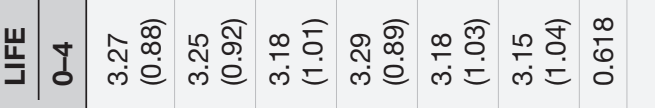

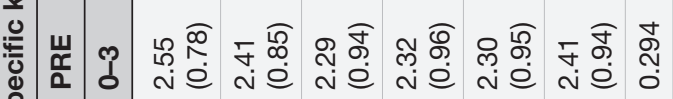

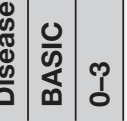

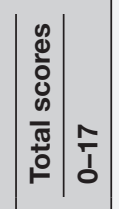

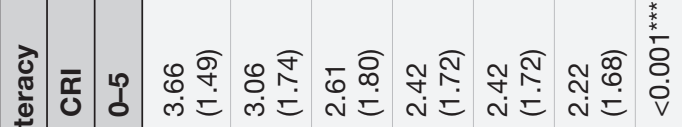

焉

萑

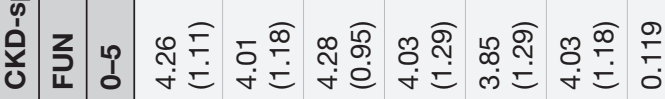

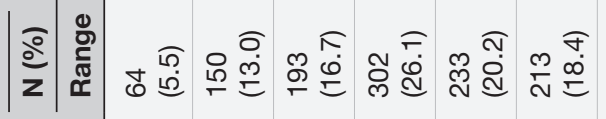

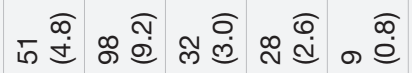

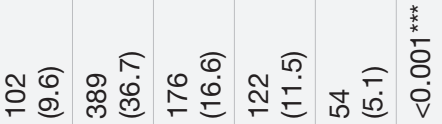

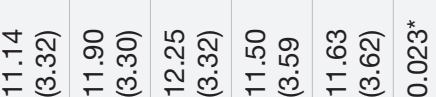

†

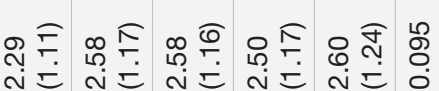

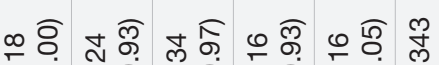

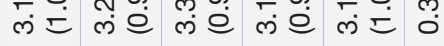

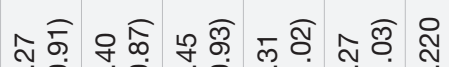
N่อ

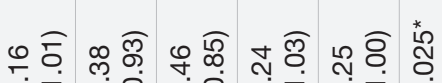
N亡

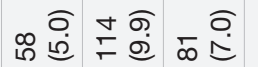

๓

จ 0 อ

夺过 苍

लి

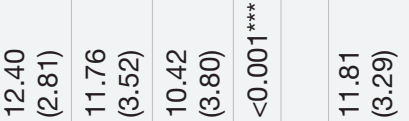

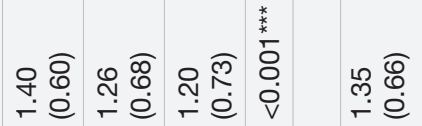

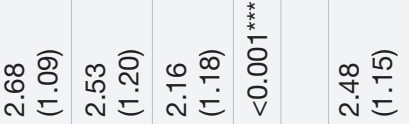

স

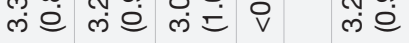

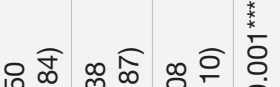

$\infty \bar{\varnothing}$

N่อ

$\infty$ 更

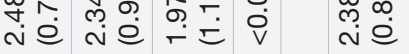

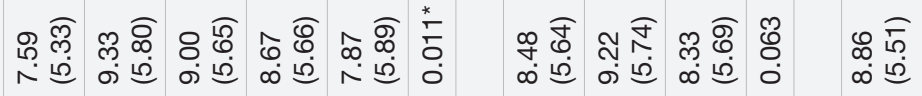

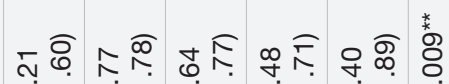

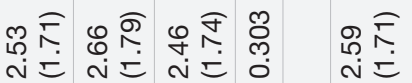

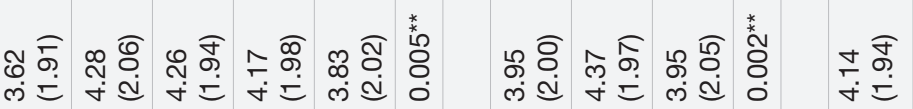

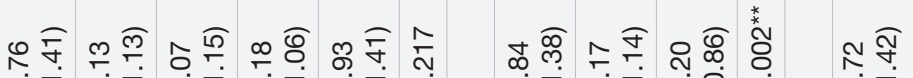

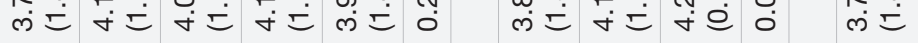

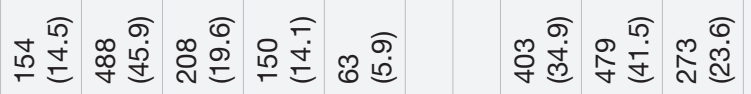
워ำ 
z

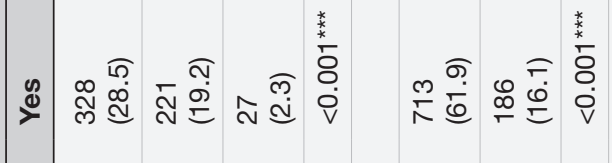

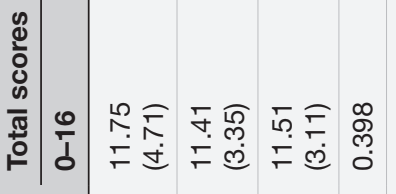

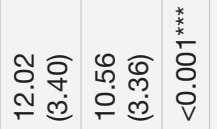

으

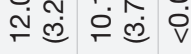

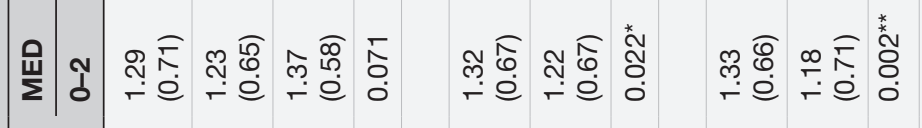

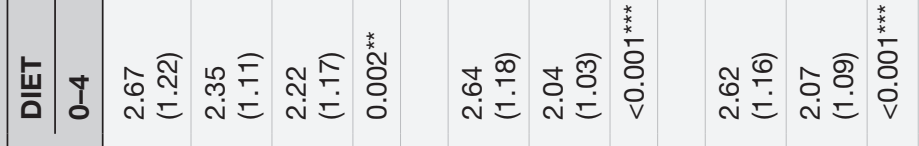

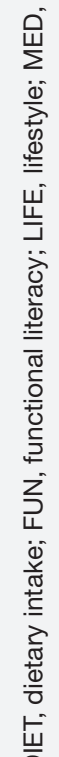

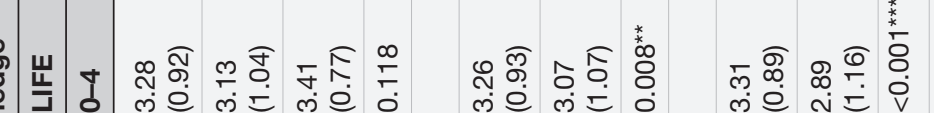

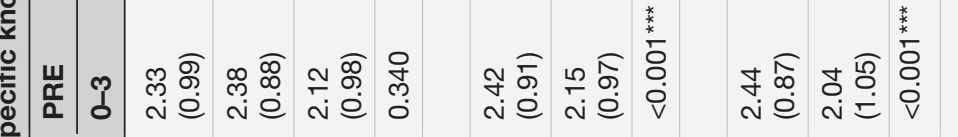

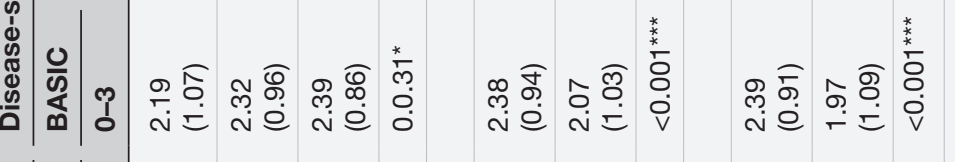

离

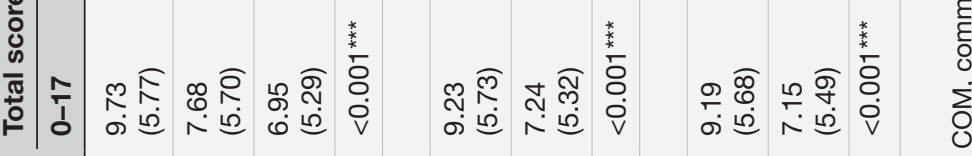

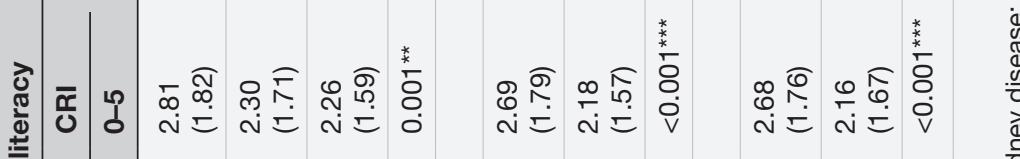

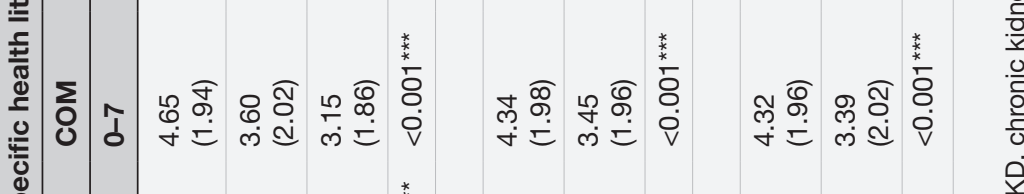

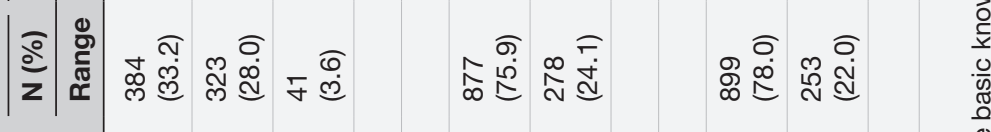

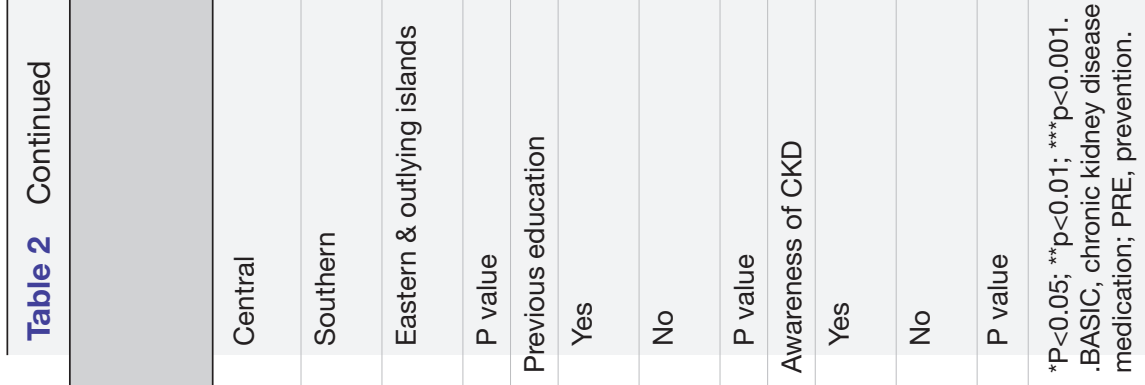


Table 3 Regression model of CKD-specific health literacy and knowledge

\begin{tabular}{|c|c|c|}
\hline & $\begin{array}{l}\text { CKD-specific } \\
\text { health literacy }\end{array}$ & $\begin{array}{l}\text { Disease-specific } \\
\text { knowledge }\end{array}$ \\
\hline & $\beta$ coefficient\# & $\beta$ coefficient\# \\
\hline \multicolumn{3}{|l|}{ Demographic variables } \\
\hline Age & $-0.33^{\star \star \star}$ & $-0.18^{\star \star \star}$ \\
\hline Years with CKD & 0.02 & 0.02 \\
\hline \multicolumn{3}{|l|}{ CKD stage (stage 1) } \\
\hline 2 & -0.06 & 0.03 \\
\hline $3 \mathrm{~A}$ & $-0.11^{*}$ & -0.03 \\
\hline 3B & $-0.12^{*}$ & 0.04 \\
\hline 4 & $-0.14^{\star \star}$ & 0.02 \\
\hline 5 & $-0.21^{\star \star \star}$ & 0.04 \\
\hline \multicolumn{3}{|l|}{ Gender (female) } \\
\hline Male & 0.04 & -0.03 \\
\hline \multicolumn{3}{|l|}{$\begin{array}{l}\text { Educational } \\
\text { attainment (primary } \\
\text { school or lower) }\end{array}$} \\
\hline Junior high & $0.13^{\star \star \star}$ & $0.12^{\star \star \star}$ \\
\hline Senior high & $0.22^{\star \star \star}$ & $0.21^{\star \star \star}$ \\
\hline College or higher & $0.29^{\star \star \star}$ & $0.25^{\star \star \star}$ \\
\hline \multicolumn{3}{|l|}{$\begin{array}{l}\text { Disease awareness } \\
\text { of CKD (no) }\end{array}$} \\
\hline Yes & $0.13^{\star \star \star}$ & $0.19^{\star \star \star}$ \\
\hline $\mathrm{R}^{2}$ & 0.34 & 0.19 \\
\hline Adjusted $\mathrm{R}^{2}$ & 0.33 & 0.18 \\
\hline F value & $44.94^{\star \star \star}$ & $20.50^{\star \star \star}$ \\
\hline
\end{tabular}

providers. ${ }^{42334}$ To reflect health literacy as it is understood in the Taiwanese context, health literacy items were developed to assess everyday obstacles encountered by patients, such as how participants respond to their friends and how they approach follow-up actions. Expanding from Nutbeam's original definition, ${ }^{13}$ local patient perspectives were also incorporated into this study, leading to an adjusted definition of health literacy as the ability to comprehend, communicate, use information and make decisions.

Participants recorded higher accuracy rates in functional literacy, basic knowledge and CKD prevention knowledge than in communicative literacy, critical literacy, dietary knowledge and medication knowledge. The lowest-scoring item in communicative health literacy-the section that covers everyday conversations between physicians and patients-was about reasons for adhering to fluid intake instructions (54.1\%), while the second-lowest scoring item asked about reasons for collecting urine samples $(72.7 \%)$. The worst performance in critical health literacy, defined as the ability to use information and make judgements, was in numeracy skill $(61.7 \%)$, which refers to the use of quantitative data to manage medication use and fluid intake, and to monitor risk. Worse numeracy skills might lead to higher risk, especially in Taiwan and China, where CKD has proven a major issue. ${ }^{634}$ In the dietary knowledge category, which involves knowing how to choose fruits, cooking oils and carbohydrates for daily meals, only $35.4 \%$ of participants with high phosphate levels chose whole grain rice for a carbohydrate, and only $57.8 \%$ of patients with pre-ESRD chose bananas for a fruit as physicians recommend. In the section on safe medication usage, only $43.6 \%$ of participants correctly identified the statement: 'Longterm use of anti-diabetic medication is highly likely to cause kidney failure in the long run.' Misunderstanding such important information related to disease management is an obstacle to patients taking a more active role in managing their condition. ${ }^{40}$ Of all the topics, dietary knowledge proved the most difficult to comprehend and apply. A greater emphasis on dietary knowledge and numeracy skills in patient instruction is therefore recommended to enhance health literacy. ${ }^{3841}$

\section{Disease awareness}

A significantly higher proportion of participants $(78 \%)$ were aware that they had CKD in this study than in other comparable studies, ${ }^{910}$ potentially indicating the success of a pay-for-performance pre-ESRD programme launched in 2006 and an early-CKD programme launched in 2011 in Taiwan. ${ }^{42} 43$ The result could also be explained through selection bias, as the participants were referred by nephrologists and therefore might understand their disease better than those who visit other types of specialists or do not visit any physicians. More thorough data collection in the future is recommended.

Participants who were aware of their disease reported significantly better health knowledge and communicative and critical health literacy than those who were not aware they had CKD. Patients who understood their disease also performed better in disease health literacy and knowledge. 8 Although a difference between genders was expected, as men are typically more reluctant to admit they have kidney disease due to its connection with sexual dysfunction, a symbol of male pride, this study showed no significant difference in CKD awareness between men and women. ${ }^{44}$ It also indicated that patients in preESRD stages do not necessarily know their disease better than those in the early stages of CKD.

\section{Implications}

From a public health perspective, helping patients embrace their illness is the first step toward disease management. From this starting point, further education on health literacy and knowledge is suggested to improve communicative and critical literacy, while disease-specific education is suggested to improve knowledge about recommended diets and medication. 


\section{Limitations}

There are three major limitations of this study. First, since all participants were recruited through nephrologist referrals, the results might not accurately reflect the status of those who visited other specialists or do not visit any physicians. Second, the results might be biased due to its cross-sectional design. Further longitudinal studies are recommended to explore causal relationships. Third, the results might not be generalisable to patients with CKD in other countries.

\section{CONCLUSION}

This CKD-specific health literacy and knowledge assessment tool developed for Mandarin and Taiwanesespeaking patients is reliable and well validated. While the participants were generally competent in functional literacy, basic knowledge and CKD prevention knowledge, the results showed room for improvement in communicative literacy, critical literacy, dietary knowledge and medication knowledge. Disease awareness played a significant role in performance, as participants who were aware they had CKD scored better on health knowledge questions and items measuring communicative and critical health literacy than those who were not aware of their condition. Patients who understood their disease also performed better than those who did not in CKD-specific health literacy and knowledge tests, showing that disease awareness is highly associated with CKD-specific health literacy and knowledge. We recommend that physicians enhance patients' awareness of their disease to inspire commitment to disease management.

\section{Author affiliations}

${ }^{1}$ Department of Public Health, Fu Jen Catholic University, Taipei, Taiwan

${ }^{2}$ Deputy Minister Office, Executive Yuan Republic of China Ministry of Health and Welfare, Taipei, Taiwan

${ }^{3}$ Division of Nephrology, Department of Internal Medicine, Tri-Service General Hospital, National Defense Medical Center, Taipei, Taiwan

${ }^{4}$ Division of Nephrology, Department of Internal Medicine, Taipei Hospital, Ministry of Health and Welfare, New Taipei City, Taiwan

${ }^{5}$ Department of Pharmacy, Tri-Service General Hospital, Taipei, Taiwan

${ }^{6}$ School of Health Care Administration, Taipei Medical University, Taipei, Taiwan

Acknowledgements The authors wish to thank all those who assisted with data collection, in alphabetical order by hospital name. Dr CG Lu (Cardinal Tien Hospital), Dr JY Wu (Chang-Hua Hospital, Ministry of Health and Welfare), ZY Huang (Changhua Christian Medical Foundation, Changhua Christian Hospital, Zhong Hua Road Branch), Dr WZ Gan (Chi Mei Hospital), Dr JZ Wang (Chi Mei Medical Foundation, Liouying Chi Mei Hospital), Dr BY Chen (Chi Mei Medical Foundation, Chiali Chi Mei Hospital), Dr ZZ Zhang (China Medical University Hospital), Dr PH Hong, ZY Huang (Ditmanson Medical Foundation Chia-Yi Christian Hospital), Dr YS Peng (Far Eastern Memorial Hospital), Dr QA Chen (Fooyin University Hospital), Dr ZR Wu (Hualien Armed Forces General Hospital), Dr YX Lai (Hualien Tzu Chi Hospital, Buddhist Tzu Chi Medical Foundation), Dr ZQ Wang (Kaohsiung Armed Forces General Hospital), Dr JC Zhang (Kaohsiung Armed Forces General Hospital, Gangshan Branch), Dr HZ Fang (Kaohsiung Veterans General Hospital), YQ Guo (Kinmen Hospital, Ministry of Health and Welfare), Dr KL Wu, Dr WF Jiang, Dr XH Huang, Dr BR Xiao (Hsin Chu Armed Force Hospital), Dr TH Ye (Postal Hospital), Dr WZ Wu (Miaoli Hospital, Ministry of Health and Welfare), Dr AF Chen, RDN YT Jiang (National Yang-Ming University Hospital), Dr YW Fang, MX Cai (Shin Kong Wu Ho-su Memorial Hospital), Dr WX Wang, YQ Huang, SW Ke, PN Wen (Taoyuan General Hospital, Sinwu Branch, Ministry of Health and Welfare), Dr JW Guo
(Taichung Armed Forces General Hospital, Taichung Armed Forces General Hospital, Zhongqing Branch), ZL Lin (Taipei Hospital, Ministry of Health and Welfare), Dr YZ Lin (Taipei Medical University Hospital), Dr YM Su (Taipei Municipal Wanfang Hospital), Dr WJ Wang, ZJ Chen (Tao Yuan General Hospital, Ministry of Health and Welfare), Dr BS Lin (Tung's Taichung MetroHarbor Hospital), Dr JH Huang (Ton-Yen General Hospital), Dr GJ Wu, Medical Educator J Ling (Tri-Service General Hospital), Dr HE Wang (Tri-Service General Hospital Keelung Branch), Dr JJ Chen (Tri-Service General Hospital Penghu Branch), Dr HY Zhu (Yang Ming Hospital), Dr WZ Liu (Yonghe Cardinal Tien Hospital), Dr YJ Liu (Yuan's General Hospital), Dr LH Zhong (Yuan Rung Hospital), and Dr YC Liu (Kaohsiung Armed Forces General Hospital, Zuoying Branch).

Contributors C-HC, C-JW, Y-JH, Y-CC, J-ZY and C-LS designed and conceived of the study, and searched for study settings. C-HC, Y-JH, Y-CC, J-ZY, C-LS, C-JW and $\mathrm{J}-\mathrm{HS}$ carried out the study, and prepared the instrument and manuscript. C-HC, C-JW and J-HS performed statistical analysis and prepared the manuscript. C-HC responded to editorial and reviewers' comments. All authors read and approved the final manuscript.

Funding This work was supported by the Health Promotion Administration, Ministry of Health and Welfare, Taiwan, ROC (MOHW105-HPA-M-114-112101, MOHW106-HPA-M-114-112101).

Competing interests None declared.

Patient consent for publication Obtained.

Ethics approval This study was approved by the Joint Institutional Review Boards of Taipei Medical University (approval number TMU-JIRB \# N201512052). All participants were fully informed and gave consent before the interview began. The informed consent form is attached as online supplemental appendix 2. All data collection conformed to ethical guidelines and research protocol.

Provenance and peer review Not commissioned; externally peer reviewed.

Data availability statement No data are available. Datasets generated and/or analyzed during the study are not publicly available due to the authors' contract with the funding agency.

Supplemental material This content has been supplied by the author(s). It has not been vetted by BMJ Publishing Group Limited (BMJ) and may not have been peer-reviewed. Any opinions or recommendations discussed are solely those of the author(s) and are not endorsed by BMJ. BMJ disclaims all liability and responsibility arising from any reliance placed on the content. Where the content includes any translated material, BMJ does not warrant the accuracy and reliability of the translations (including but not limited to local regulations, clinical guidelines, terminology, drug names and drug dosages), and is not responsible for any error and/or omissions arising from translation and adaptation or otherwise.

Open access This is an open access article distributed in accordance with the Creative Commons Attribution Non Commercial (CC BY-NC 4.0) license, which permits others to distribute, remix, adapt, build upon this work non-commercially, and license their derivative works on different terms, provided the original work is properly cited, appropriate credit is given, any changes made indicated, and the use is non-commercial. See: http://creativecommons.org/licenses/by-nc/4.0/.

\section{ORCID iD}

Chiung-Hsuan Chiu http://orcid.org/0000-0002-6030-5960

\section{REFERENCES}

1 United States Renal Disease System. 2020 annual data report; 2020.

2 United States Renal Data System. Chapter 11: international comparisons United States Renal Data System, USRDS; 2018.

3 Deng GF. The top ten of the health insurance expenditure - early psychosis first time to enter the list. United Daily News. 2018 August 5.

4 Levey AS, Schoolwerth AC, Burrows NR, et al. Comprehensive public health strategies for preventing the development, progression, and complications of CKD: report of an expert panel convened by the centers for disease control and prevention. Am J Kidney Dis 2009;53:522-35.

5 Turner JM, Bauer C, Abramowitz MK, et al. Treatment of chronic kidney disease. Kidney Int 2012;81:351-62.

6 Chen C, Zheng J, Driessnack M, et al. Health literacy as predictors of fluid management in people receiving hemodialysis in China: a structural equation modeling analysis. Patient Educ Couns 2021;104:1159-67. 
7 Vassalotti JA, Centor R, Turner BJ, et al. Practical approach to detection and management of chronic kidney disease for the primary care clinician. Am J Med 2016;129:153-62.

8 Sherwood M, McCullough PA. Chronic kidney disease from screening, detection, and awareness, to prevention. Lancet Glob Health 2016;4:e288-9.

9 Plantinga LC, Tuot DS, Powe NR. Awareness of chronic kidney disease among patients and providers. Adv Chronic Kidney Dis 2010;17:225-36.

10 Plantinga LC, Boulware LE, Coresh J, et al. Patient awareness of chronic kidney disease: trends and predictors. Arch Intern Med 2008;168:2268-75.

11 Wen CP, Cheng TYD, Tsai MK, et al. All-Cause mortality attributable to chronic kidney disease: a prospective cohort study based on 462 293 adults in Taiwan. Lancet 2008;371:2173-82.

12 Ad Hoc Committee on Health Literacy for the Council on Scientific Affairs, American Medical Association. Health literacy: report of the Council on scientific Affairs. JAMA 1999;281:552-7.

13 Nutbeam D. Health literacy as a public health goal: a challenge for contemporary health education and communication strategies into the 21st century. Health Promot Int 2000;15:259-67.

14 von Wagner C, Knight K, Steptoe A, et al. Functional health literacy and health-promoting behaviour in a national sample of British adults. J Epidemiol Community Health 2007;61:1086-90.

15 Shih C-L. The correlation of health knowledge, health status, and patient safety on the patient in Taiwan. Taipei 2007.

16 Devraj R, Gordon EJ. Health literacy and kidney disease: toward a new line of research. Am J Kidney Dis 2009;53:884-9.

17 Lora CM, Gordon EJ, Sharp LK, et al. Progression of CKD in Hispanics: potential roles of health literacy, acculturation, and social support. Am J Kidney Dis 2011;58:282-90.

18 Lai AY, Ishikawa $\mathrm{H}$, Kiuchi T, et al. Communicative and critical health literacy, and self-management behaviors in end-stage renal disease patients with diabetes on hemodialysis. Patient Educ Couns 2013;91:221-7.

19 Parker RM, Baker DW, Williams MV, et al. The test of functional health literacy in adults: a new instrument for measuring patients' literacy skills. J Gen Intern Med 1995;10:537-41.

20 Weiss BD, Mays MZ, Martz W, et al. Quick assessment of literacy in primary care: the newest vital sign. Ann Fam Med 2005;3:514-22.

21 Sørensen K, Van den Broucke S, Pelikan JM, et al. Measuring health literacy in populations: illuminating the design and development process of the European health literacy survey questionnaire (HLSEU-Q). BMC Public Health 2013;13:948.

22 Osborne RH, Batterham RW, Elsworth GR, et al. The grounded psychometric development and initial validation of the health literacy questionnaire (HLQ). BMC Public Health 2013;13:658.

23 Taylor DM, Fraser SDS, Bradley JA, et al. A systematic review of the prevalence and associations of limited health literacy in CKD. Clin J Am Soc Nephrol 2017:12:1070-84

24 Wright Nunes JA, Wallston KA, Eden SK, et al. Associations among perceived and objective disease knowledge and satisfaction with physician communication in patients with chronic kidney disease. Kidney Int 2011;80:1344-51.

25 Wright JA, Wallston KA, Elasy TA, et al. Development and results of a kidney disease knowledge survey given to patients with CKD. American Journal of Kidney Diseases 2011;57:387-95.

26 Devraj R, Wallace LS. Application of the content expert process to develop a clinically useful low-literacy chronic kidney disease self- management knowledge tool (CKD-SMKT). Research in Social and Administrative Pharmacy 2013;9:633-9.

27 Young BA. Health literacy in nephrology: why is it important? Am J Kidney Dis 2013;62:3-6.

28 Devraj R, Wallace LS. Application of the content expert process to develop a clinically useful low-literacy chronic kidney disease selfmanagement knowledge tool (CKD-SMKT). Res Social Adm Pharm 2013;9:633-9.

29 Wright JA, Wallston KA, Elasy TA, et al. Development and results of a kidney disease knowledge survey given to patients with CKD. Am J Kidney Dis 2011;57:387-95.

30 Taiwan Society Of Nephrology. Taiwan chronic kidney disease clinical guideline; 2020.

31 National Health Insurance Administration MoHaW. The operational definition of medical quality indicators.

32 United States Renal Data System U. 2014 USRDS annual data report: epidemiology of kidney disease in the United States. Bethesda, MD; 2014.

33 surveymonkey. Sample size calculation 2021.

34 Shih C-L, Chang T-H, Jensen DA, et al. Development of a health literacy questionnaire for Taiwanese hemodialysis patients. BMC Nephrol 2016;17:54.

35 National Institute of Diabetes and Digestive and Kidney Disease N. Explaining your kidney test results: a Tear-off pad for clinical use, 2014. Available: https://www.niddk.nih.gov/health-information/ professionals/clinical-tools-patient-education-outreach/explainkidney-test-results

36 Team KMUC-HMHKC. Chronic kidney disease manual. Taiwan Health Promotion Administration, Ministry of Health and Welfare; 2013.

37 Wu M. SPSS Operation and Application - The Practice of quantitative analysis of questionnaire Data. second ed. Taipei: Wu-Nan Culture Enterprise, 2009.

38 Gibbs HD. Health and nutrition literacy: what renal RDNs need to know. Renal Nutrition Forum 2017.

39 Chinn D. Critical health literacy: a review and critical analysis. Soc Sci Med 2011;73:60-7.

40 Davey J, Holden CA, Smith BJ. The correlates of chronic diseaserelated health literacy and its components among men: a systematic review. BMC Public Health 2015;15:589.

41 Yeh J-Z, Wei C-J, Weng S-F, et al. Disease-Specific health literacy, disease knowledge, and adherence behavior among patients with type 2 diabetes in Taiwan. BMC Public Health 2018;18:10.1186/ s12889-018-5972-X.

42 Hsieh H-M, Lin M-Y, Chiu Y-W, et al. Economic evaluation of a pre-ESRD pay-for-performance programme in advanced chronic kidney disease patients. Nephrol Dial Transplant 2017:32:10.1093/ndt/gfw372:1184-94.

43 Chen Y-C, Weng S-F, Hsu Y-J, et al. Continuity of care: evaluating a multidisciplinary care model for people with early CKD via a nationwide population-based longitudinal study. BMJ Open 2020;10:e041149.

44 Finkelstein FO, Shirani S, Wuerth D, et al. Therapy insight: sexual dysfunction in patients with chronic kidney disease. Nat Clin Pract Nephrol 2007;3:200-7.

$45 \mathrm{Xie}$ JJ. If the doctor said that I have "a deficiency of the kidney," does that mean I have a problem of sexual function? Should I tonify my kidney? : For a better life; 2018 [cited 201930 June]. Available from. Available: https://www.commonhealth.com.tw/article/article. action?nid=77407 